\title{
Control of a Bidirectional Single-Phase Grid Interface for Electric Vehicles
}

\author{
Matheus Montanini Breve ${ }^{1,2}$ (D) and Vicente Leite ${ }^{2(凶)}$ (D) \\ 1 Universidade Tecnológica Federal do Paraná, Cornélio Procópio, Brazil \\ matheus.m.breve@gmail.com \\ 2 Research Centre in Digitalization and Intelligent Robotics (CeDRI), \\ Instituto Politécnico de Bragança, Bragança, Portugal \\ avtl@ipb.pt
}

\begin{abstract}
The number of electric vehicles is expected to increase exponentially in the next decade. This represents a huge potential for grid support, such as energy storage in their batteries, with advantages for grid operators and for customers. For this purpose, flexible power interfaces are required. This paper presents a simulation of a bidirectional singlephase power interface between an electric vehicle battery and the grid. The proposed system is fully simulated and counts with features such as vehicle-to-grid, vehicle-to-home and grid-to-vehicle. All power flow and the controllers for these modes of operation are described in detail. The simulation was developed in a Software-in-the-Loop scheme to facilitate a future physical implementation with a Hardware-in-the-Loop platform. The proposed system was extensively tested via simulation, the results proving the system is stable, able to change operation modes smoothly and definition of the exchanged active and reactive powers.
\end{abstract}

Keywords: Bidirectional interface $\cdot$ Electric vehicle $\cdot \mathrm{V} 2 \mathrm{G} \cdot \mathrm{V} 2 \mathrm{H}$

\section{Introduction}

According to estimations from the International Energy Agency (IEA) around 120 million electric vehicles (EV) will be on the road globally by 2030 [1]. Thus, EVs might serve as a distributed energy storage system that can be integrated with the electric grid [2-4].

This integration was first devised in 1997 [2] and has since been frequently referred as vehicle-to-grid (V2G) technology [3], with its various aspects being analyzed in depth by many authors [5-8]. If V2G technology is adopted by the majority of EV owners, it has the potential to be not only useful to grid operators, but to customers as well. Enabling information and power exchange between grid operators and electric vehicles owners would allow customers to optimize charging based on electricity prices, for example. Grid operators, on the other hand, could benefit from an additional grid stabilization source, which could prove useful in a scenario where the usage of photovoltaic energy and wind energy is also growing.

(C) Springer Nature Switzerland AG 2020

S. Nesmachnow and L. Hernández Callejo (Eds.): ICSC-CITIES 2019, CCIS 1152, pp. 285-299, 2020. https://doi.org/10.1007/978-3-030-38889-8_22 
The possibility of a bidirectional power flow could also be used to power homes during short electricity shortages and electric grid instabilities, technology called Vehicle-to-Home (V2H). Vehicle-to-Home is one of the features built in the latest model of the aforementioned Nissan Leaf [9]. V2H could help reduce consumption of grid power in periods of the day when demand is highest and thus costlier, or simply as a backup power supply in case of emergencies. This technology, explored for example in [10,11], could become important taking into account the expanding connectivity between home appliances in a Smart Home scenario and the growing number of households with renewable energy sources, like photovoltaics (PV).

In this context, this paper presents the simulation of a bidirectional singlephase power interface between an electric vehicle and the grid with MATLAB ${ }^{\circledR}$ and Simulink. The presented system counts with features such as grid-to-vehicle (G2V) for battery charging, vehicle-to-grid (V2G) for grid support and vehicleto-home (V2H), as well as allowing seamless transitions between these operation modes. The simulation is assembled in a Software-in-the-Loop (SiL) scheme with the power and control structures simulated in the discrete domain and with different simulation rates. This allows for future testing in a Hardware-in-theLoop (HiL) platform, for which only small parameter adjustments are needed.

The paper is divided in five sections, the first being a brief introduction about concepts such as V2G and V2H and their relevance. The second section contains details on the implemented system structure, such as the control algorithms employed and power topology used. The third section explains the computational model created in Simulink and the simulation results are listed in the fourth section. The fifth and last section contains the conclusions.

\section{System Structure}

The power structure chosen to accomplish the integration of an electrical vehicle with the electric grid is arranged in a dual-stage configuration and composed of five parts. This structure is the most commonly employed [12] and counts with two dedicated power processors, similar to the structure employed in $[10,13,14]$. The parts are:

- Vehicle, represented as a battery;

- Bidirectional DC/DC converter (BDC);

- Bidirectional single-phase voltage-source inverter (BADC or VSI);

- Output filter to reduce current harmonic distortion;

- Grid and common-coupling point (CPP).

A simplified block diagram of the proposed system structure can be seen in Fig. 1. The connection lines between the blocks represent the bidirectional nature of the power flow in the system. 


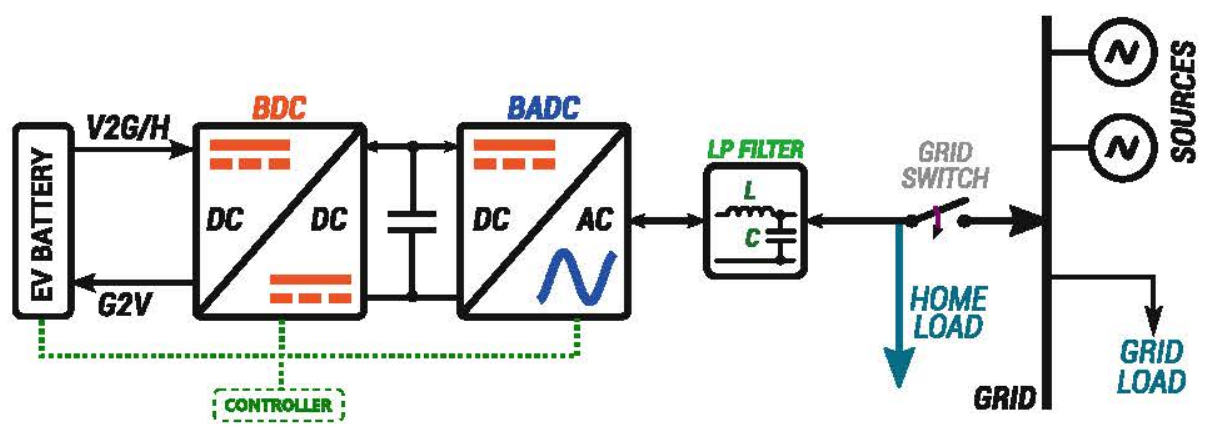

Fig. 1. Proposed system structure

\subsection{Power Topology}

Figure 2 shows the power topology of the bidirectional interface in greater detail. The bidirectional DC/DC converter (BDC) is a power converter that alternates between two modes of operation, step-down (buck) and step-up (boost) modes, respectively charging (G2V) and discharging the battery (V2G and V2H).

The bidirectional single-phase voltage-source inverter (BADC) is a full-bridge inverter with two IGBT inverter legs and free-wheel diodes. The output filter is a low-pass LC filter to lower the harmonic distortion in the inverter current output waveform. The grid is represented by an AC source with capability of exchanging any given amount of active and reactive power, thus acting as an infinite bus. The common-coupling point represents where home loads can be connected to and the point which, after a grid fault condition is detected, remains energized in case the V2H feature is enabled.

The power structure is controlled by two control algorithms, the BDC and BADC control algorithms. Table 1 contains a summary of the system operation modes and the control targets of the BDC and BADC control algorithms.

Table 1. Summary of system operation modes and the respective control targets of the DC/DC and DC/AC converters

\begin{tabular}{l|l|l|l|l}
\hline \multicolumn{3}{l|}{ Operation modes } & Control target \\
\hline Mode & Grid tied & Battery & BDC & BADC \\
\hline G2V & Yes & Charging & CV and CC charging & DC bus voltage \\
\hline V2G & Yes & Discharging & DC bus voltage & P and Q \\
\hline V2H & No & Discharging & DC bus voltage & AC voltage \\
\hline
\end{tabular}

\subsection{BDC Control Structure}

The BDC control strategy can be divided in three subsystems, as shown in Fig. 3. 


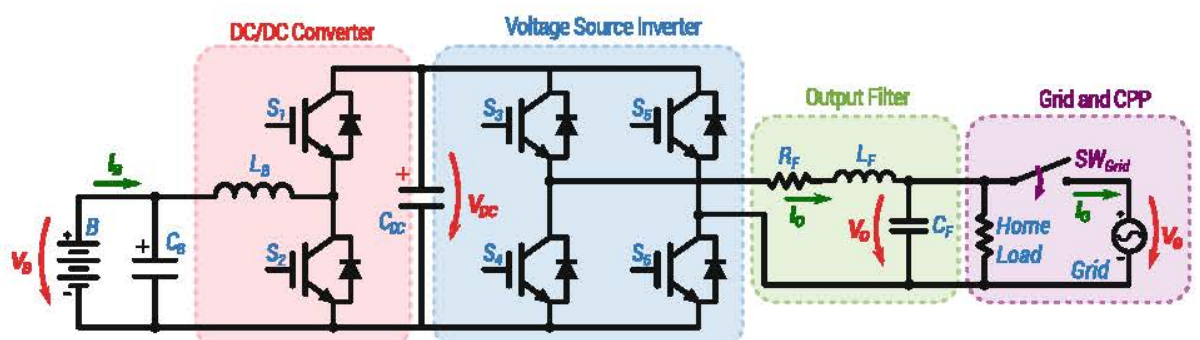

Fig. 2. Proposed power structure

The "Charging Current Reference Generator (G2V)" subsystem generates a battery current reference, $I_{B}^{*}$, to control the charging current in G2V mode. The battery charging current is determined by two charging modes, constant current (CC) and constant voltage (CV). In CC charging mode the current reference $I_{B_{\mathrm{CC}}}^{*}$ can be set to equal the maximum or a given percentage of the battery nominal charge current. In CV charging mode a PI controller generates a battery current reference, $I_{B \mathrm{CY}}^{*}$, to maintain the battery voltage constant.

The "Discharging Current Reference Generator (V2G/H)" subsystem contains a PI controller that will determine the battery current needed to maintain the DC link voltage constant at a set voltage. This $V_{\mathrm{DC}}$ control method is used both in V2G (grid-connected) and V2H (grid-isolated) modes.

The "Battery Current Controller" subsystem controls the BDC PWM duty cycle to maintain the battery current at the setpoint, in turn given by the two aforementioned subsystems. It contains a PI controller comparing the battery current reference $I_{B}^{*}$, given by the two aforementioned subsystems, and the measured battery current value $I_{B}$, generating a BDC control signal. This signal is converted to a PWM signal generator to drive the IGBT gates in the BDC converter to achieve the desired battery current.

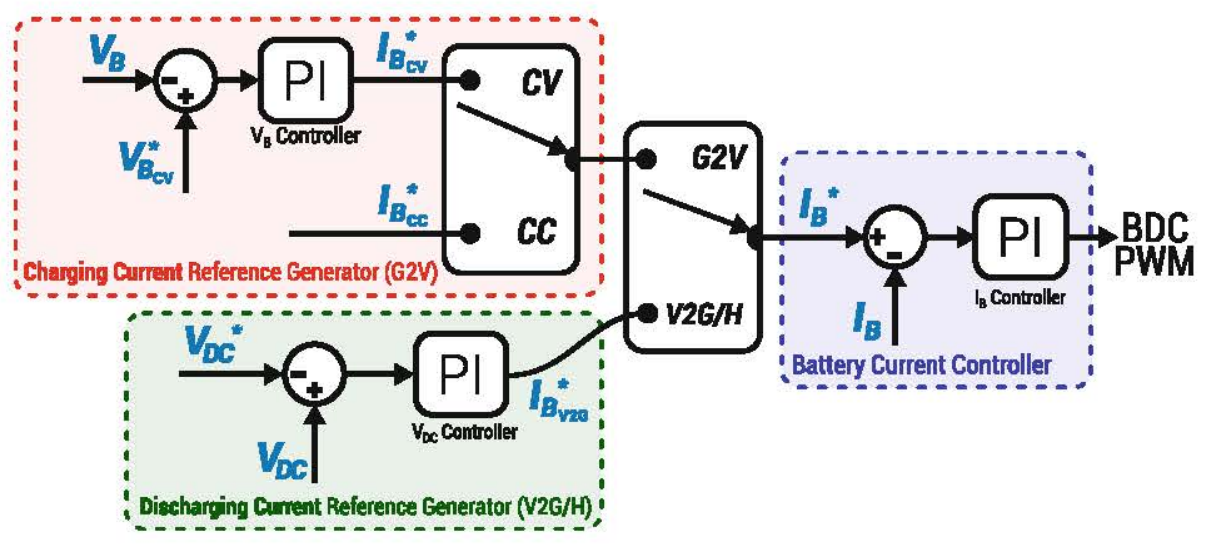

Fig. 3. Proposed BDC control structure 


\subsection{BADC Control Structure}

The BADC control algorithm can be subdivided in two different modes: the grid-connected and grid-isolated modes.

Grid connected modes include the G2V and V2G operation modes. An overview of the grid-connected control algorithm is shown in greater detail in Fig. 4. The system operating in G2V mode is responsible for controlling the battery charging current and voltage. In V2G mode it controls the active and reactive power exchange with the grid. The control algorithm of the two gridconnected operation modes are explained as it follows:

- V2G mode: in V2G mode, the active and reactive power are set externally by $P_{\mathrm{REF}}$ and $Q_{\mathrm{REF}}$. Since the active power delivered to the grid is proportional to the output current d-component, $i_{d}$, and the reactive power proportional to the output current q-component, $i_{q}$, converting these power quantities into the desired $d q$-components of the output current requires power calculations in $d q$-theory. These calculations result in $d q$-current references, $i_{O d}^{*}$ and $i_{O q}^{*}$, which are fed into classical PI controllers, that in turn give out $V_{d}^{\prime}$ and $V_{q}^{\prime}$, called voltage demand values [15].

- G2V mode: in G2V mode the VSI is responsible for maintaining the DC link voltage constant, acting similar to the BDC in V2G mode. In this mode a PI controller compares the DC link voltage, $V_{\mathrm{DC}}$, with the reference value, $V_{\mathrm{DC}}^{*}$, and generates the needed current to be extracted from the grid and injected into the DC link $I_{\mathrm{DC}}^{*}$ to maintain the DC bus voltage constant. An unitary power factor is also maintained, since the q-component of the grid current is kept null, unless reactive power compensation while charging the battery is needed. Thus, in this mode there is a $180^{\circ}$ phase difference between the VSI voltage and current output.

As displayed in Fig. 4 the $d q$-current controllers only calculate the demand values $V_{d}^{\prime}$ and $V_{q}^{\prime}$. In order to obtain the true $V_{d}$ and $V_{q}$ values, a process called decoupling is necessary. Decoupling takes into account the dynamics of the inverter AC-side, including output filter. Signals such as $\theta_{\mathrm{PLL}}$ and $\left\|V_{G}\right\|_{\text {PLL }}$ represent respectively the grid voltage phase and amplitude, needed for grid synchronization. These signals are calculated via a Phase-Locked Loop (PLL) based on the structure devised in [16].

\subsection{Grid-Isolated Mode (V2H)}

The transition from grid-connected to grid-isolated mode is activated following the detection of a grid fault by the grid fault detection module. This module detects large frequency or amplitude variations in the grid voltage and, if the manually-defined thresholds are surpassed, it sends a signal ordering the disconnection from the grid, opening the grid switch as shown in Fig. 1. If the grid-isolated mode is allowed, the system control algorithm changes following the fault detection and it starts operating in grid-forming mode, also called grid-isolated mode, disconnecting itself from the grid. 


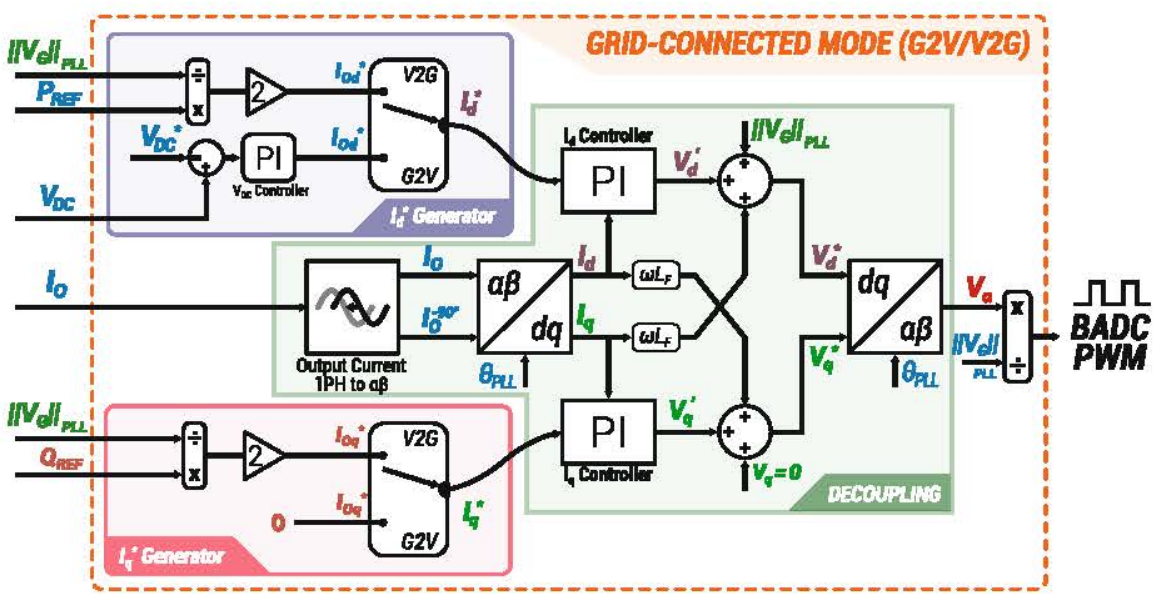

Fig. 4. Proposed BADC current control structure in grid-connected modes

In grid-isolated mode (V2H) the VSI must be controlled with a fixed sinusoidal voltage reference, since grid synchronization is not possible, being the system responsible for generating a grid. This voltage reference in $\mathrm{V} 2 \mathrm{H}$ mode is obtained via the system represented in Fig. 5.

This system uses a fixed frequency reference, $50 \mathrm{~Hz}$, to generate a signal $\omega t$ via a discrete integrator. The maximum value of $\omega t$ is limited $2 \pi$, that is, $360^{\circ}$, given that the integrator is reset when $\omega t$ reaches this value. An initial phase, $\theta_{0}$, given by a PI controller for re-synchronization with the grid, is added to the resulting signal and the sum $\omega t+\theta_{0}$ is converted into a sinusoidal reference with a 230 V RMS value. The peak voltage is divided by the DC link voltage to obtain the PWM reference signal corresponding to a $230 \mathrm{~V}$ RMS output.

The voltage output requires a closed-loop control as shown to ensure a steady $V_{\mathrm{RMS}}^{*}$ voltage regardless of the load, up to the specified inverter power limits. The controller output is limited to a $\pm 5 \%$ variation to prevent over-voltage conditions.

\subsection{Grid Re-synchronization}

In the event of grid reconnection in stand-alone (V2H) mode, the VSI output might be at a different frequency or out-of-phase in relation to the grid voltage and thus a grid re-synchronization strategy is required. For that, an initial phase, $\theta_{0}$, is given by a PI controller. The controller compares and reduces the difference between the grid and output phase by altering the initial phase value, which is added to the resulting signal generator. The phase difference is calculated by converting the grid and output phase signals into sinusoidal signals and then the difference between them. This results in another sinusoidal signal, whose amplitude relates to the phase difference. This way it is possible to define a threshold value and, if the calculated RMS value, that is, the difference, is lower 


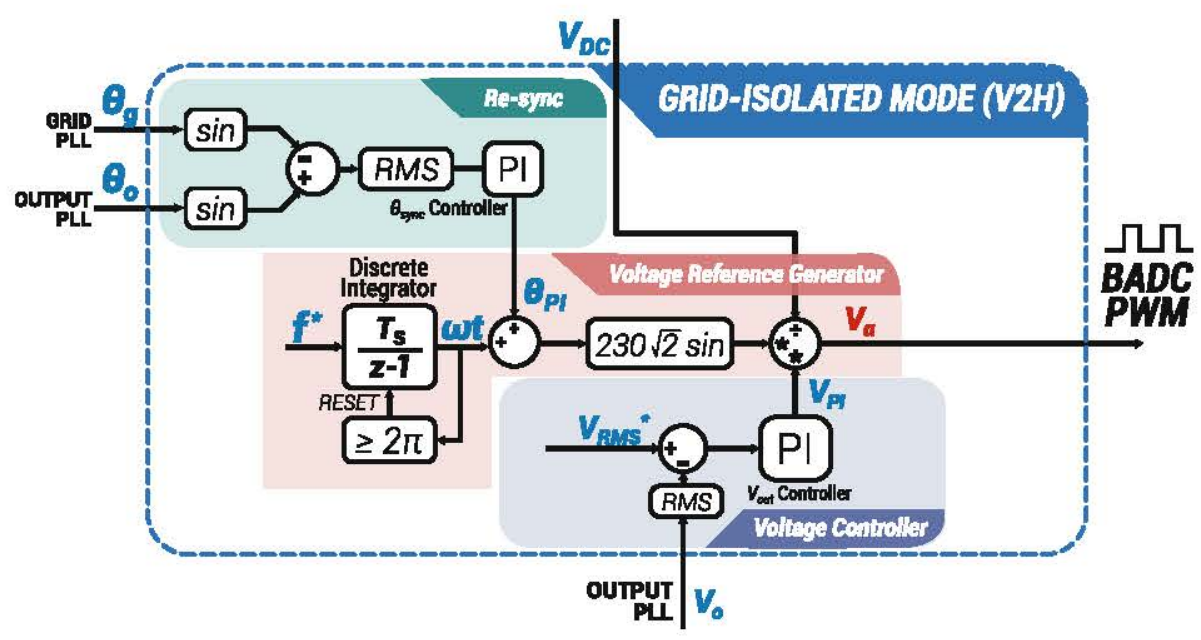

Fig. 5. Voltage reference generator in grid-isolated (V2H) mode

than the threshold the system reconnects itself with the grid, thus enabling seamless transition between grid-isolated and grid-connected operation modes.

\section{Computational System Model}

This section concerns the methods and materials used to create a computational model (Fig.6) of the power structure as shown by Fig. 7 and the respective control algorithms as displayed in Fig. 8.

Figure 6 shows that the main parameters are set externally, that is, an external user or higher-hierarchy controller can determine the operation mode while grid-connected (G2V/V2G), the power to be exchanged with the grid (power references), if the grid-isolated mode (V2H) is allowed and if the system is enabled. This reflects a the context in which higher-hierarchy controllers determine the needed V2G services, that is, what each vehicle with this system will provide.

The simulation of the system was carried out with the software MATLAB ${ }^{\circledR}$ and Simulink by MathWorks, as well as the Specialized Power Systems library under Simscape.

The power structure was developed and simulated in the discrete domain with a simulation step time of $2 \mu \mathrm{s}(500 \mathrm{kHz})$. The power structure is shown in Fig. 7.

The control algorithms are simulated with a longer simulation step time of $100 \mu \mathrm{s}(10 \mathrm{kHz})$ and are displayed in Fig. 8. Thus, the simulation was developed in a Software-in-the-Loop (SiL) scheme to facilitate a future physical implementation with a Hardware-in-the-Loop (HiL) platform.

The computational model reflects the experimental platform found in the Polytechnic Institute of Bragança (IPB), that counts with a real-time control interface based on the dSPACE DS1103 Controller Board and IGBTs switches 


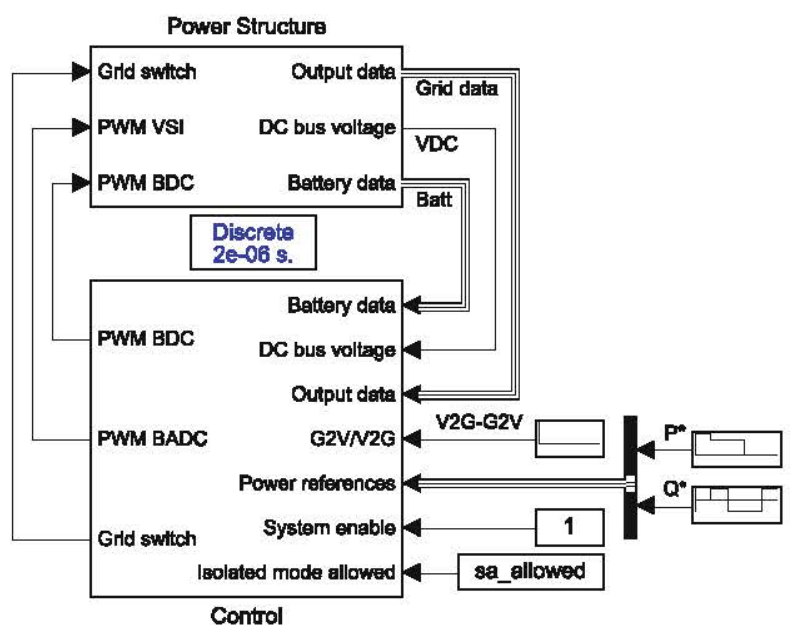

Fig. 6. SiL system representation modelled in Simulink

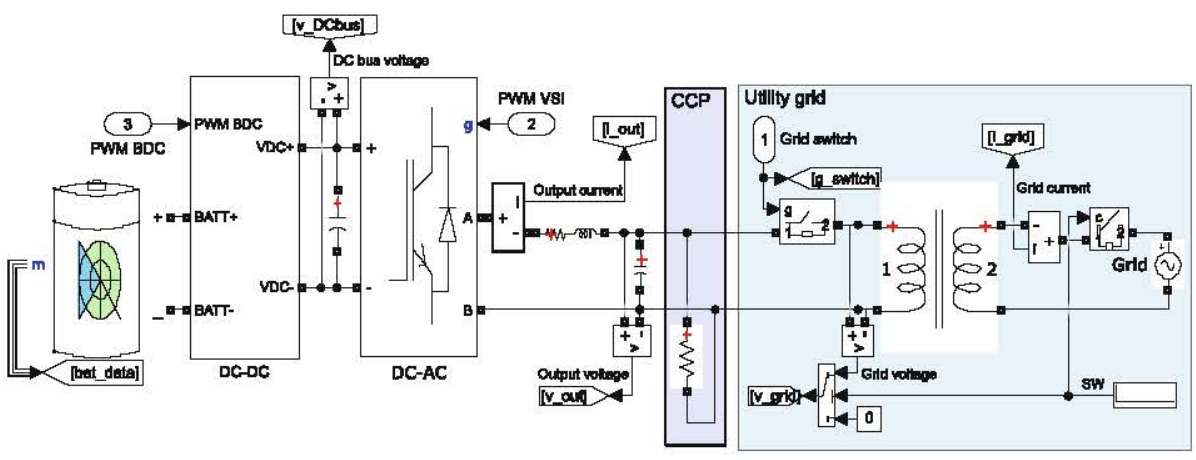

Fig. 7. Power structure modelled in Simulink

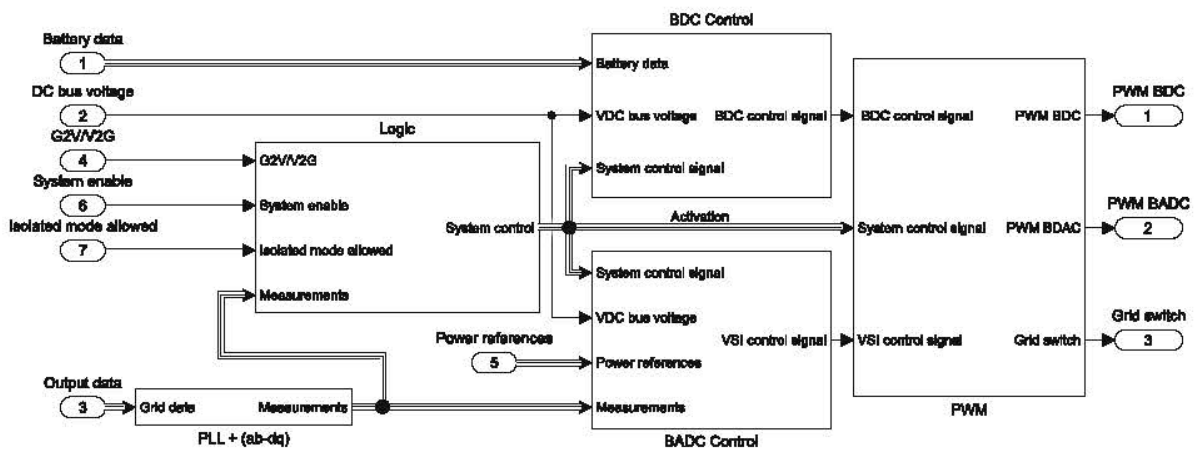

Fig. 8. Control structure modelled in Simulink 


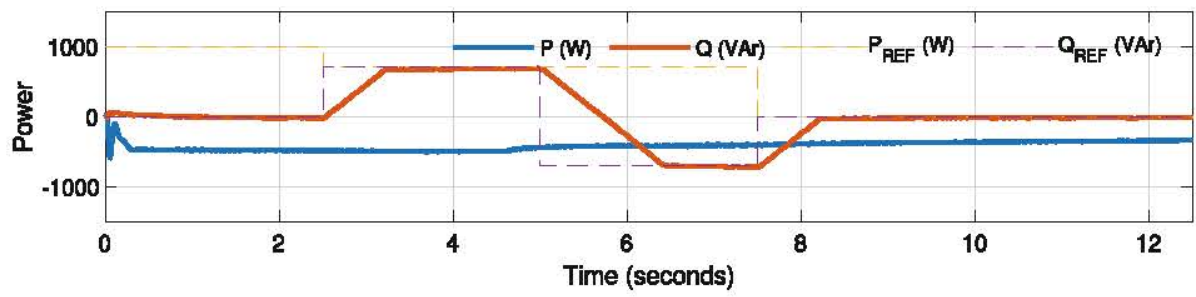

Fig. 9. Power references and measured power in G2V mode

in the PM75RLA120 power module with a maximum switching frequency of $10 \mathrm{kHz}$, the frequency used to simulate the power system representation.

\section{Computational Results}

The following results demonstrate the different system modes of operation, including operation while connected to an electric grid, thus including V2G and G2V operation modes with varying power references, as well as the V2H operation mode and the transitions between the main modes of operation.

\subsection{Operation in Grid-to-Vehicle (G2V) Mode}

During continuous G2V operation the grid current phase is opposed to that of the voltage, that is, a $180^{\circ}$ phase difference. In this simulation the active and reactive power references were also varied during the simulation to show operation in 4 different power combinations:

- CC charging mode and null reactive power;

- CC charging mode and $700 \mathrm{VAr}$;

- CV charging mode and -700 VAr;

- CV charging with null reactive power.

Since the active power withdrawn from the grid is defined by the battery charging algorithm - approximately $490 \mathrm{~W}$ in constant-current mode, the active power reference is given either by the $\mathrm{CC}$ or $\mathrm{CV}$ charging schemes.

The active power in G2V mode is not set externally, but rather internally by the battery charging controller. This can clearly be seen in Fig. 9 where the power reference line does not have any influence on the power being withdrawn from the grid to charge the battery. A change between different charging modes can also be seen at the $5 \mathrm{~s}$ mark, showing the change from a CC to a CV charging scheme. The reactive power can be set externally and, thus, the system can simultaneously charge the battery and act as an active power factor corrector if needed.

Figure 10 shows the current and voltage outputs in 3 power combinations while operating in G2V mode. 

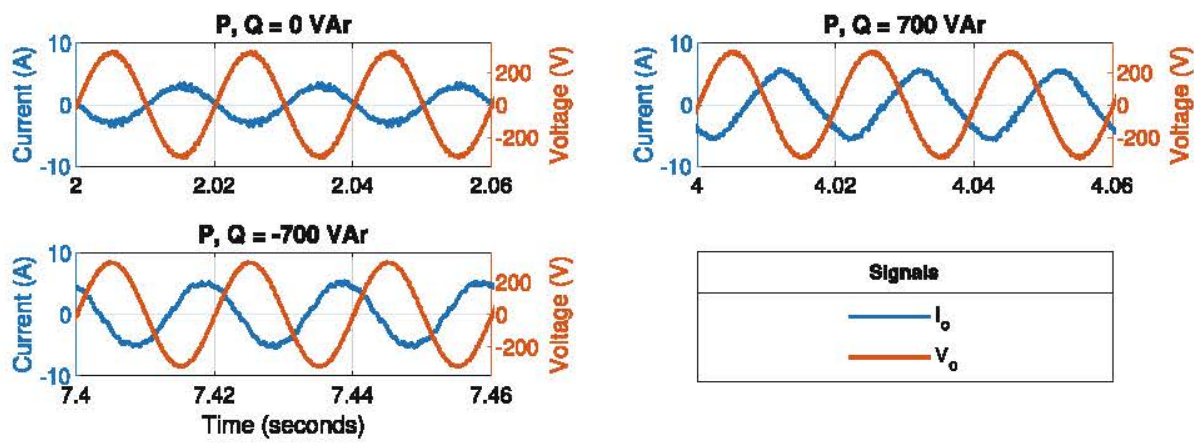

Fig. 10. VSI output current waveform in G2V mode

\subsection{Operation in Vehicle-to-Grid (V2G) Mode}

In this simulation the active and reactive power references were varied during the simulation. The simulation lasts $12.5 \mathrm{~s}$ and shows the system operating in 5 different power combinations, reflecting the existence of an external controller to determine the needed power in a micro-grid, for example. The tested power combinations are listed as it follows:

$-1000 \mathrm{~W}$ and null reactive power;

$-700 \mathrm{~W}$ and $700 \mathrm{VAr}$

$-700 \mathrm{~W}$ and $-700 \mathrm{VAr}$;

$-0 \mathrm{~W}$ and $-700 \mathrm{VAr}$;

$-0 \mathrm{~W}$ and $700 \mathrm{VAr}$.

Figure 12 shows the results obtained in this mode of operation. It shows the power references set externally, that is, the active and reactive powers desired, and the measured power exchanged with the grid, which follow these external parameters. The results prove that the system is able to operate in two power quadrants, that is, with positive active power - delivered to the grid - and either consuming or injecting reactive power (Fig. 11).
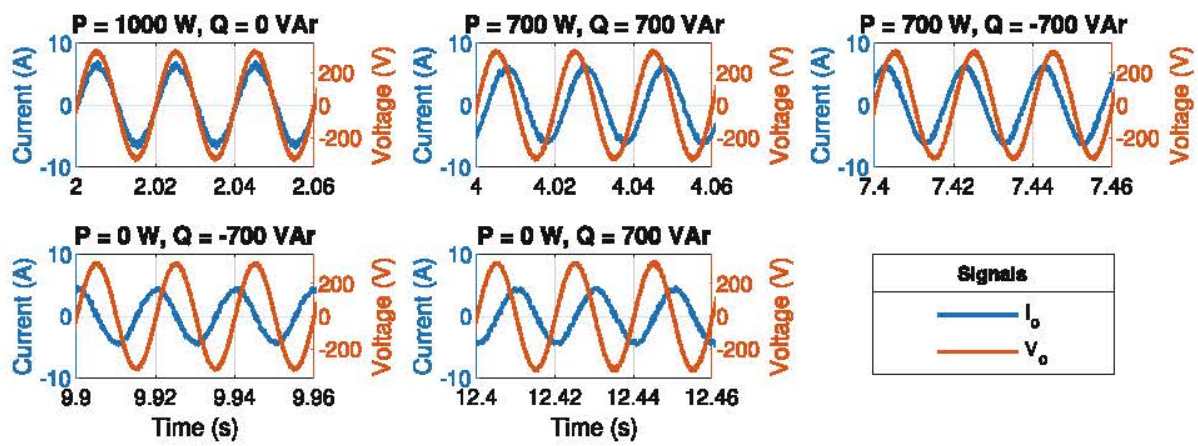

Fig. 11. VSI output current waveform in V2G mode 


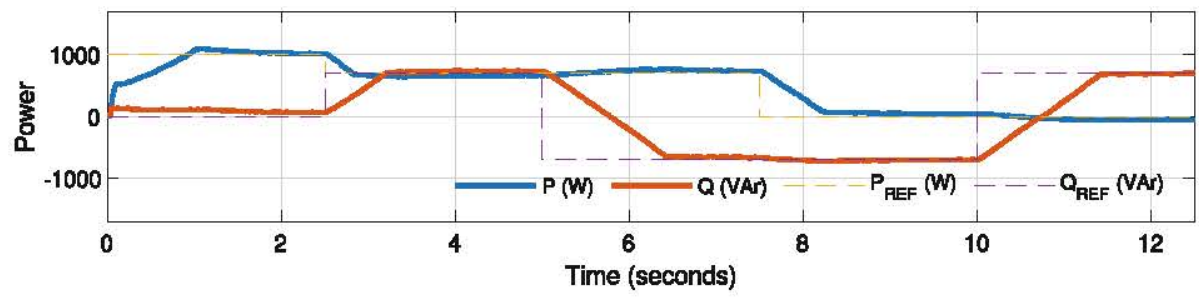

Fig. 12. Active and reactive power at VSI output and their reference values in V2G operation mode

\subsection{Grid-Tied Operation Mode Transitions}

The following results, visible in Figs. 13 and 14, prove the system capability of switching between V2G and G2V operation modes maintaining system stability. All the switching operations are only performed when the output current crosses zero in order to reduce transients.

Figure 13 exhibits the VSI output current waveform, output power, DC link voltage and the battery voltage and current during the transition from G2V to V2G. The transition is requested at the $2 \mathrm{~s}$ mark, but executed at the next current zero crossing. Figure 13 shows the transition of the current phase in relation to the grid voltage, from being in-phase before the $2 \mathrm{~s}$ mark and becoming in opposite phase after the $2 \mathrm{~s}$ mark.

Figure 14 exhibits the VSI output current waveform, output power, DC link voltage and the battery voltage and current during the transition from V2G to G2V. The transition is requested at the $2 \mathrm{~s}$ mark, but executed at the next current zero crossing. Figure 14 shows the transition of the current phase in relation to the grid voltage, from being in opposite phase before the $3 \mathrm{~s}$ mark and becoming in-phase after the $3 \mathrm{~s}$ mark.

\subsection{Seamless Transition - From Stand-Alone to Grid-Connected}

This subsection contains the results obtained by simulating the system gridisolated feature (V2H), including the seamless transition and smooth grid resynchronization strategy after a grid reconnection is detected. For this test the grid voltage was set to be leading 45 degrees compared to the $\mathrm{V} 2 \mathrm{H}$ voltage reference.

Figure 15 shows more details of the re-synchronization and transition processes from V2H to V2G and Fig. 16 from V2H to G2V. Both figures display the output and grid phases, the error between them, the grid status, the current and voltage waveforms and the power output during these test conditions.

The transition from V2H to grid-tied operation modes is always executed when a voltage zero-crossing is detected to ensure a smooth transition. Complete re-synchronization takes approximately $3.2 \mathrm{~s}$ starting after detecting the grid presence for $\mathrm{G} 2 \mathrm{~V}$ and $1 \mathrm{~s}$ for V2G. 

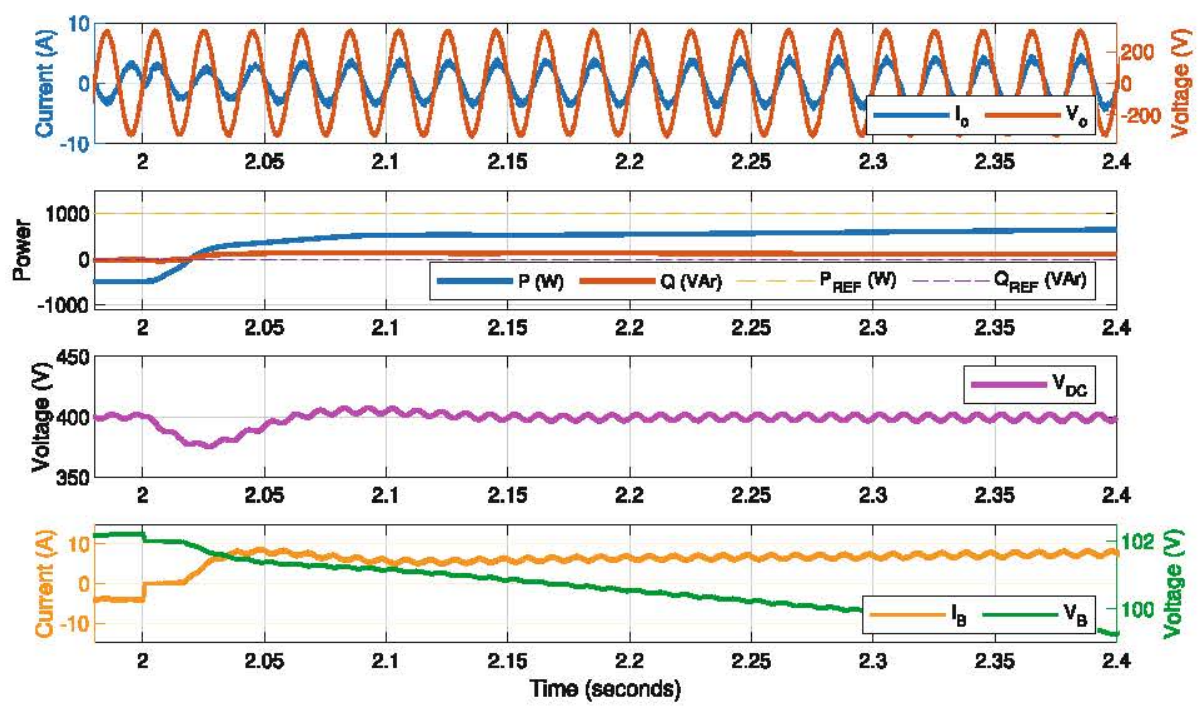

Fig. 13. VSI output current waveform, output power, DC link voltage and battery voltage and current during transition from G2V to V2G.
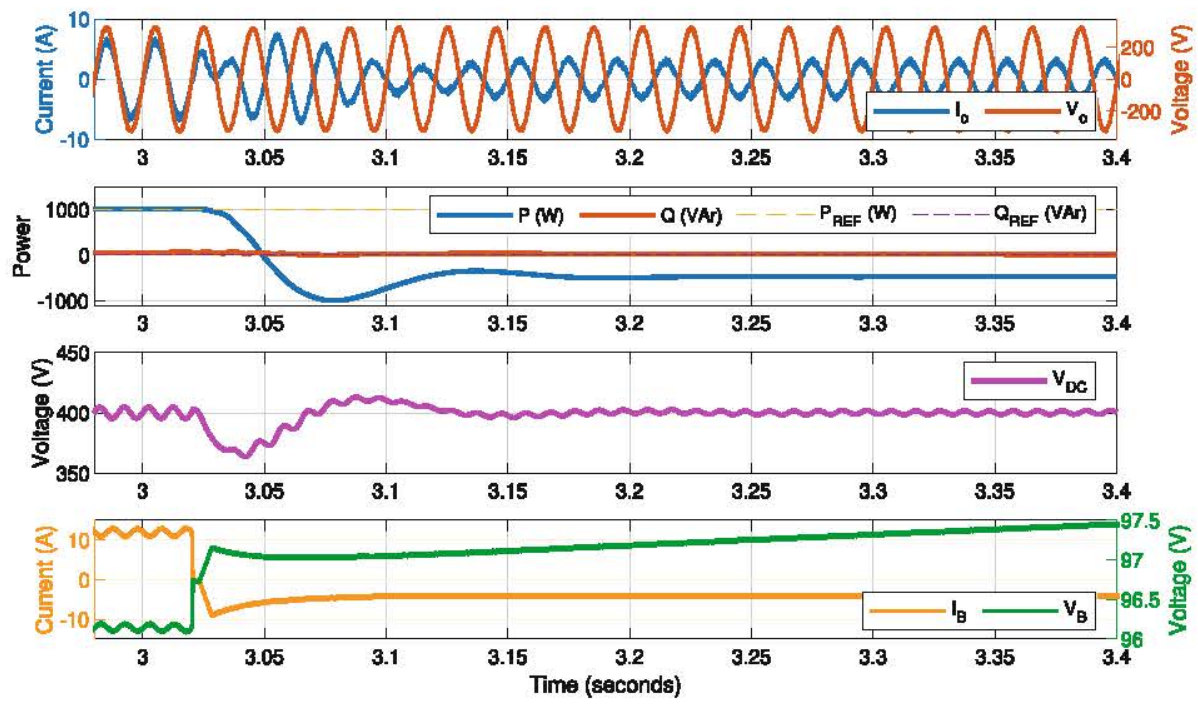

Fig. 14. VSI output current waveform, output power, DC link voltage and battery voltage and current during transition from V2G to G2V. 

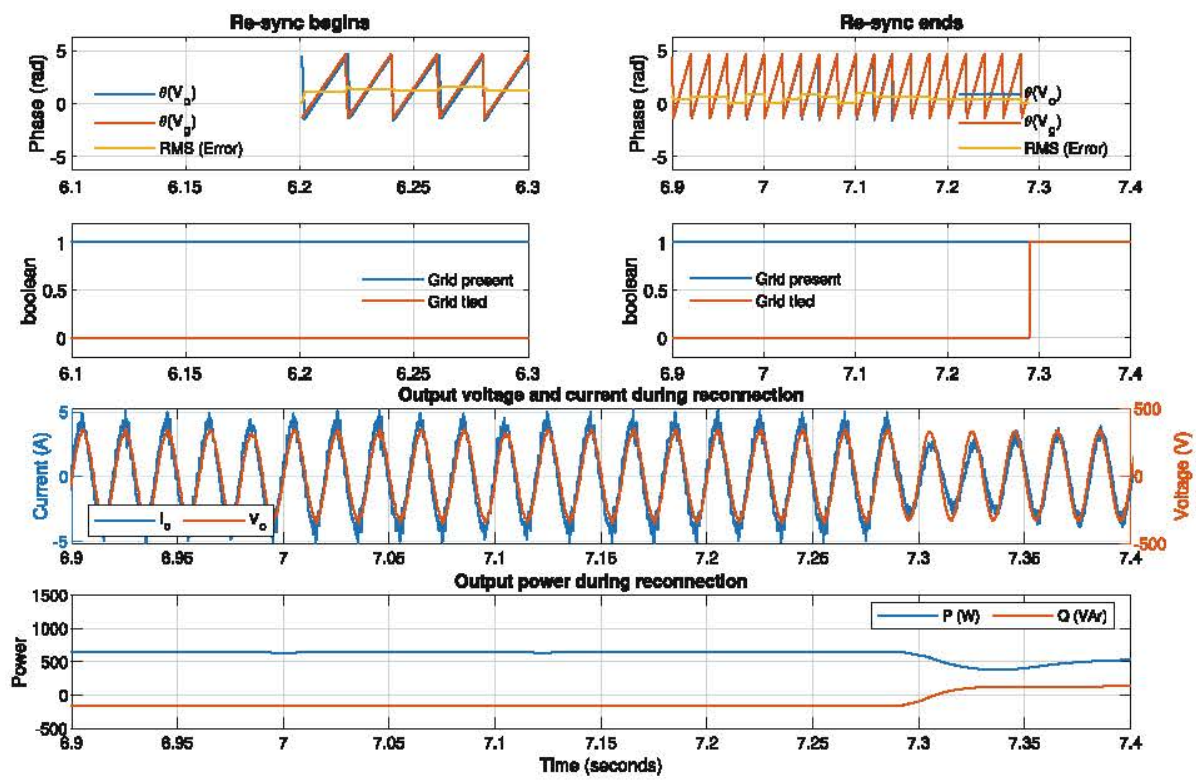

Fig. 15. Re-synchronization and transition from grid-isolated (V2H) to grid-tied V2G mode.
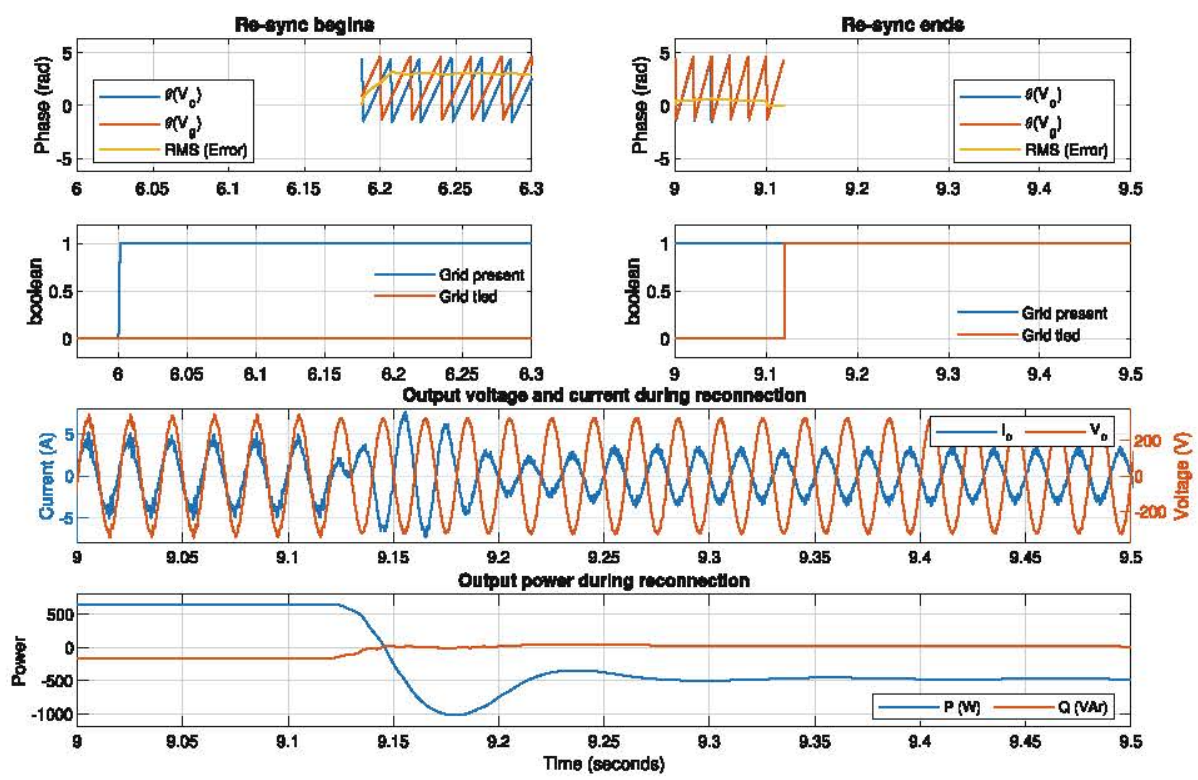

Fig. 16. Re-synchronization and transition from grid-isolated (V2H) to grid-tied G2V mode. 


\section{Conclusions}

The implementation of a single-phase bidirectional power interface between an electric vehicle battery and the grid was successful, based on the achieved computational results presented in this paper. Tests were performed in the simulation to extensively test the system and prove it is stable under different operation conditions and with varying power references. The system proved capable of dealing well with external requests or events such as mode transitions or grid faults as well, maintaining stability and with small transients.

Since the proposed system is controlled externally, that is, an external user is able to set the active and reactive power to be exchanged, decide whether the battery should be charged or discharged and if the grid-isolated mode is permitted, the proposed system is useful in the context of higher-hierarchy controllers to determine the needed V2G services. This way it is possible for grid operators or aggregators, for example, to determine which service each vehicle will provide, controlling numerous vehicles as a fleet and coordinating, based on other factors such as current battery levels, state of health, user preferences, the duration and type of services to be provided.

A simulation-validated system in which all these features are packed together, that is, battery charging in two different modes (G2V), grid support (V2G), grid-isolated (V2H), reactive power compensation, as well as allowing manual selection of the operation mode and switching between them smoothly, is not found in any of the literature cited within this document.

Besides that, the simulation here presented was developed in a Software-inthe-Loop scheme, thus, physical implementation of the system with a Hardwarein-the-Loop becomes a natural next step, being part of the planned future works related to this paper. The physical implementation will be performed with the experimental platform found in the IPB, that counts with a real-time control interface based on the dSPACE DS1103 Controller Board.

Summary of Acronyms. G2V - grid-to-vehicle; V2G - vehicle-to-grid; V2H vehicle-to-home; BDC - bidirectional DC/DC converter; BADC - bidirectional DC/AC converter; VSI - voltage-source inverter; CC - constant current; CV - constant voltage; HiL - Hardware-in-the-Loop; SiL - Software-in-the-Loop.

\section{References}

1. International Energy Agency: Global EV Outlook 2018: towards cross-modal electrification. https://webstore.iea.org/global-ev-outlook-2018

2. Kempton, W., Letendre, S.E.: Electric vehicles as a new power source for electric utilities. Transp. Res. Part D: Transp. Environ. 2(3), 157-175 (1997) http://www.sciencedirect.com/science/article/pii/S1361920997000011

3. Kempton, W., Tomić, J.: Vehicle-to-grid power fundamentals: calculating capacity and net revenue. J. Power Sources 144(1), 268-279 (2005) 
4. Kempton, W., Tomić, J.: Vehicle-to-grid power implementation: From stabilizing the grid to supporting large-scale renewable energy. J. Power Sources 144(1), 280294 (2005)

5. Sovacool, B.K., Axsen, J., Kempton, W.: The future promise of vehicle-to-grid (V2G) integration: a sociotechnical review and research agenda. Annu. Rev. Environ. Resour. 42(1), 377-406 (2017)

6. Tan, K.M., Ramachandaramurthy, V.K., Yong, J.Y.: Integration of electric vehicles in smart grid: a review on vehicle to grid technologies and optimization techniques. Renew. Sustain. Energy Rev. 53, 720-732 (2016)

7. Mwasilu, F., Justo, J.J., Kim, E.K., Do, T.D., Jung, J.W.: Electric vehicles and smart grid interaction: a review on vehicle to grid and renewable energy sources integration. Renew. Sustain. Energy Rev. 34, 501-516 (2014)

8. Ferdowsi, M.: Plug-in hybrid vehicles - a vision for the future. In: 2007 IEEE Vehicle Power and Propulsion Conference, pp. 457-462, September 2007

9. Nissan: Vehicle to Home Electricity Supply System. https://www.nissan-global. com/EN/TECHNOLOGY/OVERVIEW/vehicle_to_home.html

10. Pinto, J.G., et al.: Bidirectional battery charger with grid-to-vehicle, vehicle-togrid and vehicle-to-home technologies. In: IECON 2013-39th Annual Conference of the IEEE Industrial Electronics Society, pp. 5934-5939, November 2013

11. Vittorias, I., Metzger, M., Kunz, D., Gerlich, M., Bachmaier, G.: A bidirectional battery charger for electric vehicles with V2G and V2H capability and active and reactive power control. In: 2014 IEEE Transportation Electrification Conference and Expo (ITEC), pp. 1-6, June 2014

12. Sharma, A., Sharma, S.: Review of power electronics in vehicle-to-grid systems. J. Energy Storage 21, 337-361 (2019)

13. Leite, V., Ferreira, A., Batista, J.: Bidirectional vehicle-to-grid interface under a microgrid project. In: 2014 IEEE 15th Workshop on Control and Modeling for Power Electronics (COMPEL), pp. 1-7, June 2014

14. Zgheib, R., Al-Haddad, K., Kamwa, I.: V2G, G2V and active filter operation of a bidirectional battery charger for electric vehicles. In: 2016 IEEE International Conference on Industrial Technology (ICIT), pp. 1260-1265, March 2016

15. Samerchur, S., Premrudeepreechacharn, S., Kumsuwun, Y., Higuchi, K.: Power control of single-phase voltage source inverter for grid-connected photovoltaic systems. In: 2011 IEEE/PES Power Systems Conference and Exposition, pp. 1-6, March 2011

16. Ciobotaru, M., Teodorescu, R., Blaabjerg, F.: A new single-phase PLL structure based on second order generalized integrator. In: 2006 37th IEEE Power Electronics Specialists Conference, pp. 1-6, June 2006 